\title{
Correction to: Identification of a group 16SrIX 'Candidatus Phytoplasma phoenicium' phytoplasma associated with sweet orange exhibiting decline symptoms in Iran
}

\author{
Ali Abbasi $^{1} \cdot$ Nader Hasanzadeh $^{1}$ - Maryam Ghayeb Zamharir ${ }^{2} \cdot$ Masoud Tohidfar $^{3}$ \\ Published online: 16 September 2019 \\ C Australasian Plant Pathology Society Inc. 2019
}

Correction to: Australasian Plant Disease Notes (2019) 14:11 https://doi.org/10.1007/s13314-019-0342-9

This article is part of a $\mathrm{PhD}$ thesis of the first author, with work being carried out both at Azad University and AREEO listed as A. Abbasi's affiliations in the original version. However, due to a subsequent change in university rules, the university affiliation must be used exclusively in order for the work to be considered as part of the first author's $\mathrm{PhD}$ thesis. The authors therefore are required to adjust the author affiliations.

The online version of the original article can be found at https://doi.org/ 10.1007/s13314-019-0342-9

Maryam Ghayeb Zamharir

zamharir2005@yahoo.com

1 Department of Plant Protection, Faculty of Agricultural Sciences and Food Industries, Science \& Research Branch of Islamic Azad University, Tehran, Iran

2 Plant Diseases Department, Iranian Research Institute of Plant protection, Agricultural Research, Education and Extension Organization (AREEO), Tehran, Iran

3 Biotechnology Group, Department of New Technology and Energy Engineering, Shahid Beheshti University, Tehran, Iran 